\title{
Alkali Etched Nanoporous Silicon Graphene Composite as Sodium Ion Battery Anode
}

\author{
W. Wazeer ${ }^{1}$, M. M. Nabil ${ }^{1}$, M. Feteha ${ }^{2}$, M. B. Soliman ${ }^{2}$, A. E. Kashyout ${ }^{1, *}$
}

${ }^{1}$ Electronic Materials Department, Advanced Technology and New Materials Research Institute, City of Scientific Research and Technological Applications (SRTA-City), P.O. Box 21934, New Borg El-Arab City, Alexandria, Egypt.

${ }^{2}$ Materials Science Department, Institute of Graduate Studies and Research, Alexandria University, 163 Horrya Avenue, P.O. Box 832, Shatby, 21526 Alexandria, Egypt.

*Corresponding author: E-mail: hady8@yahoo.com

Received 14 October 2021

Revised 29 October 2021

Accepted for publication 9 November 2021

Published online 9 November 2021

\section{Abstract}

A simple and fast method is used for the preparation of nano-porous silicon ( $\mathrm{Si}$ ) and porous silicon-graphene composites ( $\mathrm{Si}$ $\mathrm{G}$ ) as an anode material for the application of sodium-ion batteries. The fabrication method includes the ball milling technique for mixing the silicon powder and graphene for five minutes with an alkaline etching solution. The produced nano powder is characterized using energy dispersive X-ray analysis (EDAX), X-ray diffraction (XRD), scanning/transmission electron microscope (SEM/TEM), and Raman spectroscopy for investigating their composition, morphology, and structural properties. The amount of the oxidized silicon (silica) is about four times in graphene-containing sample indicating catalytic power of high surface area carbon. Also, Si-G nanocomposite is characterized by the presence of sodium residues that might be strongly adsorbed to carbon. The reversible capacities reported for $\mathrm{Si}$ and $\mathrm{Si}-\mathrm{G}$ samples are 15.7 and $84 \mathrm{mAhg}^{-1}$ respectively. The columbic efficiencies for those samples are $7 \%$ and $40 \%$. The EIS shows a remarkable reduction in $\mathrm{R}_{\mathrm{CT}}$ value for Si-G anodes and increases in its ionic conductivity.

Keywords: Nanoporous silicon; Graphene; Nanocomposite; Sodium-ion Battery; Si-G nanocomposite.

\section{Introduction}

Intercalation chemistry was discovered by the Noble prized Stanley Whittingham in the early 70th to put the basics of lithium and sodium-ion batteries. The outstanding success of lithium-ion batteries (LIBs) delayed the interest for SIBs until the lithium depletion warnings have been declared [1]. The materials experimented as SIBs electrodes are quite similar to those experimented with LIBs electrodes, but with replacing $\mathrm{Li}$ element with $\mathrm{Na}$ in an intercalation active compound. The materials tried as SIBs anodes were much less fortunate than those tried as SIBs cathodes [2]. Among the early used SIBs anodes are sodium metal and its alloys. They are suffering from dendrite formation issues during recycling, which is the main problem reported for $\mathrm{Li}$ metal in LIBs [3]. Carbon-based anodes in SIBs do not fulfill the requirements for fast charge in SIBs.
The commercial graphite anodes couldn't intercalate $\mathrm{Na}^{+}$ions reversibly as $\mathrm{Li}^{+}$ions. Expanded graphite and hard carbon are the most extensively studied carbon-based anodes for SIBs [4]. Titaniumbased anodes as anatase $\mathrm{TiO}_{2}$ and sodium-titanate are advantaged by their high stability, but their electronic conductivity and $\mathrm{Na}^{+}$ionic conductivity are low, which lower their power density as anodes [5,6]. Sodium terephthalate was examined by et al. As an organic material, they possess the features of flexibility and lightweight, leading to the advantages of easy fabrication ability and high gravimetric theoretical capacity. On the other hand, Naterephthalate was reported to undergo a partial dissolution in organic electrolytes that are commonly used in SIBs, leading to loss of capacity upon cycling [7]. Alloy-based anode materials as P, Sn, Sb, Si, and 
Ge were known as "P-block elements" having high capacities as LIBs anode materials [8].

The silicon anodes for LIBs were able to form $\mathrm{Li}_{15} \mathrm{Si}_{4}$ alloy resulting in a theoretical capacity of $3580 \mathrm{mAh}$ $\mathrm{g}^{-1}$. On the other side, crystalline $\mathrm{Si}$ was electrochemically inactive at room temperature owing to a large $\mathrm{Na}$ ion diffusion barrier [9]. Only the orthorhombic silicon was reported as active for sodium alloying, forming $\mathrm{Na}_{4} \mathrm{Si}_{24}$, having a theoretical capacity of only $160 \mathrm{mAh} \mathrm{g}^{-1}$, which is insufficient due to the presence of the first irreversible capacity that is normally recorded in anodes. In addition, in both SIBs and LIBs, they suffer from high unit cell volumetric expansion during charging (up to $300 \%$ ), causing capacity fading after a few cycles [10].

Amorphous silicon is, theoretically, able to form an alloy with sodium to form $\mathrm{Na}_{0.76} \mathrm{Si}$, with a theoretical capacity of about $725 \mathrm{mAh} \mathrm{g}^{-1}[11,12]$. Practically, Xu et al. prepared hybrid crystalline/amorphous $\mathrm{Si}$ nanoparticles with a ratio of 0.39:0.61 using thermal plasma chemical vapor deposition of silane. It showed a reversible capacity of $279 \mathrm{mAhg}^{-1}$ (at a low current of $10 \mathrm{mAg}^{-1}$ ) with capacity retention of $89 \%$ after 100 cycles [13]. Nanoporous silicon (NPS) - graphene composite is suggested in this work to be used instead of intact - nonporous - silicon nanoparticles that have been used in LIBs anode. The porosity of Si NPS is expected to enhance the ability of particles for volume change and allow more convenient $\mathrm{Na}$ ion movement [14].

\section{Experimental}

\subsection{Active material synthesis}

Two starting materials were used, a pure silicon powder (99\%, Acros, Germany) and a mixture of silicon with graphite nanoplatelets (industrial quality graphite nanoplatelets, ACS material, USA) with a ratio of $2: 1$. The two samples are signed as $(\mathrm{Si})$ and $(\mathrm{Si}-$ $\mathrm{G})$ respectively.

A total of $3 \mathrm{~g}$ of each sample was ball milled at $400 \mathrm{rpm}$ for 5 min with $5 \mathrm{ml} \mathrm{NaOH}$ (min 99\%, Carl Roth GmbH, Germany) solution (8 wt\% in Milli-q water) and $5 \mathrm{ml} \mathrm{n}$ propanol (30 $\mathrm{Vol} \%)$, the total solution volume was $10 \mathrm{ml}$. The ball milling machine is Fritsch Pulverisette 7, Germany, and the ball to powder ratio was 1:20. The produced slurry was washed many times using Milli-Q water, filtered, and dried at $50{ }^{\circ} \mathrm{C}$ overnight. The resulting powder was kept in a dry jar to prevent the oxidation of reactive $\mathrm{Si}$ powder.

\subsection{Material characterization}

Elemental composition of is analyzed using EDAX unit associated with JEOL JSM- 6360 LA, Scanning Electron Microscope (SEM). Structural is analyzed using Shimadzu- XRD- 6000 Diffractometer, Japan, and Raman spectroscopy (SENTERRA, Bruker, Germany). Morphological studies are made by scanning electron microscope (JEOL JSM- 6360 LA SEM, Japan) and particle size analyzer (Beckman coulter N5 submicron PSA, USA). For PSA analysis, the powder samples are prepared by dispersing $2 \mathrm{mg}$ of powder in $5 \mathrm{ml}$ Dimethyl Sulfoxide (DMSO) and sonication in an ultrasonic bath for 30 minutes.

\subsection{Electrochemical Characterization}

\subsubsection{Electrode preparation}

Electrodes are prepared by mixing active materials with conductive carbon (industrial quality graphite nanoplatelets, ACS material, USA) using ball milling at $400 \mathrm{rpm}$ for $30 \mathrm{~min}$. N-methyl pyrrolidone (NMP) (99.5\%, Merck, Germany) containing $20 \mathrm{mg} / \mathrm{ml}$ PVDF (99\%, Alfa Aesar, Germany) is added to the mixture. The final weight ratio of (active material: conductive carbon: PVDF) is $(75: 15: 10)$. The slurry has been plated on copper foil while the unloaded parts of the current collectors are covered with isolating tape. The current collectors with an area of $1 \mathrm{~cm}^{2}$ are weighed before and after material loading. The weight of conductive additive and binder are subtracted to determine the active mass loading in the electrodes.

\subsubsection{Cell fabrication}

Electrochemical cells are two-electrode systems. The working electrode acts as the anode, sodium metal as both the counter and reference electrodes with an approximate area of $1.13 \mathrm{~cm}^{2}$, fiberglass filter paper (GFD Wattman, UK) as the separator, and $1 \mathrm{M} \mathrm{NaClO}_{4}$ (99\% Across, Germany) in propylene carbonate (PC) (99\%, Fluka, Germany) as the electrolyte. The components are assembled inside a homemade Teflon coin cell with an internal diameter of $11 \mathrm{~mm}$. Cell assembly is conducted under a dry air-filled glove box.

\subsubsection{Electrochemical Assessment}

The electrochemical experiments are conducted using an Autolab workstation (Aut 87070). The capacity is calculated from galvanic charge/discharge by the formula ( $\mathrm{I} x \mathrm{t} / \mathrm{m})$, where $\mathrm{I}$ is the applied current $(\mathrm{mA}), \mathrm{t}$ is the discharge time (hour), and $\mathrm{m}$ is the 
loading weight of active materials (grams). The first discharge curve is considered as the irreversible capacity. CV and impedance are also performed using the same cell. $\mathrm{CV}$ range is from 0 to $3 \mathrm{~V}$ and the scanning rate is $0.1 \mathrm{~V} / \mathrm{S}$. EIS is made at the open circuit potential of each electrode in a frequency range from $1 \mathrm{MHz}$ to $0.2 \mathrm{~Hz}$.

\section{Results and discussion}

Alkali etching process is a low-cost and environmentally friendly method that has been used for increasing the specific surface area of silicon powder [15]. The use of ball mail for a short time reduces the energy cost of the fabrication process. The mechanism of alkali etching is presented in equations $1-4$.

$$
\begin{aligned}
& { }^{*} \mathrm{Si}+2 \mathrm{NaOH}+2 \mathrm{H}_{2} \mathrm{O} \underset{\text { Pressure }}{\stackrel{\text { Ball mill }}{\longrightarrow}} \mathrm{SiO}_{2}(\mathrm{OH})_{2}{ }^{-2}+2 \mathrm{Na}^{+}+\mathrm{H}_{2} \\
& \mathrm{SiO}_{2}(\mathrm{OH})_{2}{ }^{-2}+2 \mathrm{Na}^{+}+\mathrm{H}_{2} \longrightarrow \mathrm{Si}^{*}+2 \mathrm{Na}^{+}+4 \mathrm{OH}^{-} \\
& \longrightarrow \mathrm{Si}(\mathrm{OH})_{4}{ }^{*}+2 \mathrm{Na}^{+}+2 \mathrm{e}^{-} \\
& \mathrm{Si}+4 \mathrm{e}^{-}+4 \mathrm{H}_{2} \mathrm{O}+2 \mathrm{Na}^{+} \longrightarrow \mathrm{Si}^{*}+2 \mathrm{NaOH}+2(\mathrm{OH})^{-}+ \\
& 2 \mathrm{H}_{2} \\
& \mathrm{Si}(\mathrm{OH})_{4}{ }^{*} \longrightarrow \mathrm{SiO}_{2}+2 \mathrm{H}_{2} \mathrm{O}
\end{aligned}
$$

This treatment produces a surface etched silicon powder, the other soluble components $(\mathrm{NaOH}$ and isopropanol) are washed out by filtration. The color of pure silicon powder is converted from grey color to dark brown color after the etching process. This is because $\mathrm{Si}$ atoms of the different crystal planes have different activation energies for the etching reaction. The $\mathrm{NaOH}$ etching of $\mathrm{Si}$ is not diffusion-limited but etching-rate-limited, the etching process takes place anisotropically: The (100) and (110) planes are much more rapidly etched compared to the stable (111) plane [16]. The role of isopropyl alcohol in the alkali etching technique is to suppress the etching rate at (100) planes in alkaline solutions [17]. The EDAX graph for samples Si and Si-G is presented in Figure 1, the results of elemental analysis are summarized in Table 1. In addition to silicon and carbon, the formation of silica and the presence of sodium residues due to the etching process are also detected. The amount of oxidized silicon (silica) is about four times in graphenecontaining sample indicating catalytic power of high surface area carbon. Also, the $\mathrm{Si}-\mathrm{G}$ sample is characterized by the presence of sodium residues that might be strongly adsorbed to carbon. XRD patterns of sodium iron phosphate $\mathrm{Fe} 3$ group samples are presented in Figure 2. The crystal structure matches (JCPDS \#01-079-0613) with face-centered cubic
(FCC) diamond structure $(\mathrm{a}=\mathrm{b}=\mathrm{c}=5.431 \AA$ ), space group Fd-3m (no 227) [18]. There is no presence of peaks for crystalline silicon dioxide in both samples, graphite peak appears at $2 \Theta$ of $26.37^{\circ}$ for the Si-G sample. The absence of peaks around $2 \Theta$ of $10.7^{\circ}$ (specific to graphene oxide) indicates that no oxidation process had occurred for graphite and only silicon is oxidized during the etching process [19]. Crystallite sizes calculated for the prepared samples by applying Scherer's equation for (111), (220), and (311) planes are summarized in Table 2 . The crystallite sizes for sample $\mathrm{Si}$ and $\mathrm{Si}-\mathrm{G}$ samples do not show large differences, indicating that the process of alkali etching has an insignificant effect on silicon's crystal structure. The amorphous silica part of the material also may participate in the capacity as it was used as anode for lithium-ion batteries [20]. Raman spectra for anode samples are presented in Figure 3. The main onephonon peak that appears at $510 \mathrm{~cm}^{-1}$ is related to $\mathrm{Si}$, beside the peaks at 295 and $934 \mathrm{~cm}^{-1}$ which are also related to silicon structure [21]. No other peaks appear for both samples except the relatively weak D band and $\mathrm{G}$ band at 1340 and $1580 \mathrm{~cm}^{-1}$ respectively which are related to graphite structure in $\mathrm{Si}-\mathrm{G}$ sample. The absence of $\mathrm{SiC}$ peaks at around $790 \mathrm{~cm}^{-1}$ indicates that there is no chemical binding between silicon and carbon, and only physical mixing had occurred [22]. Amorphous silica peak that is broad and very weak appeared at around $446 \mathrm{~cm}^{-1}$ and hidden by the strength of $\mathrm{Si}$ peaks due to their low proportion on the silicon particle's surface [23].

SEM images of Si and Si-G samples at different magnification powers are shown in Figure 4. Si samples show un-uniform particles with rough surface due to etching. Si-G sample shows a uniform distribution of graphite particles with silicon, with apparent lower particle sizes and enhanced homogeneity. The mean particle size measured manually from SEM is compared with PSA results in Table 3, particle size distribution curve obtained from PSA is shown in Figure 5.

SEM images show the presence of many particles with microscale in pure Si samples (left). This is due to the fact that ball milling with alkaline etching technique cannot be performed for long times, this is because hydrogen evolution during reaction may cause an explosion of milling vessel due to increasing pressure [24]. On the other side (right), SiG samples are more homogenous in particle size and shape. The presence of graphene during the ball milling alkaline etching process acts as a solid lubricant and prevents the formation of silica bridges between milled particles [25]. 
Table 1. Elemental analysis of the anode samples.

\begin{tabular}{|l|l|l|l|l|l|l|l|l|}
\hline \multirow{2}{*}{ Sample } & \multicolumn{2}{|c|}{ Si } & \multicolumn{2}{c|}{ C } & \multicolumn{2}{c|}{ O } & \multicolumn{2}{c|}{ Na } \\
\cline { 2 - 9 } & Wt\% & At\% & Wt\% & At\% & Wt\% & At\% & Wt\% & At\% \\
\hline Si & 96.86 & 95.34 & - & - & 3.14 & 4.66 & - & - \\
\hline Si-G & 52.03 & 33.32 & 35.18 & 52.59 & 12.02 & 13.48 & 0.77 & 0.6 \\
\hline
\end{tabular}
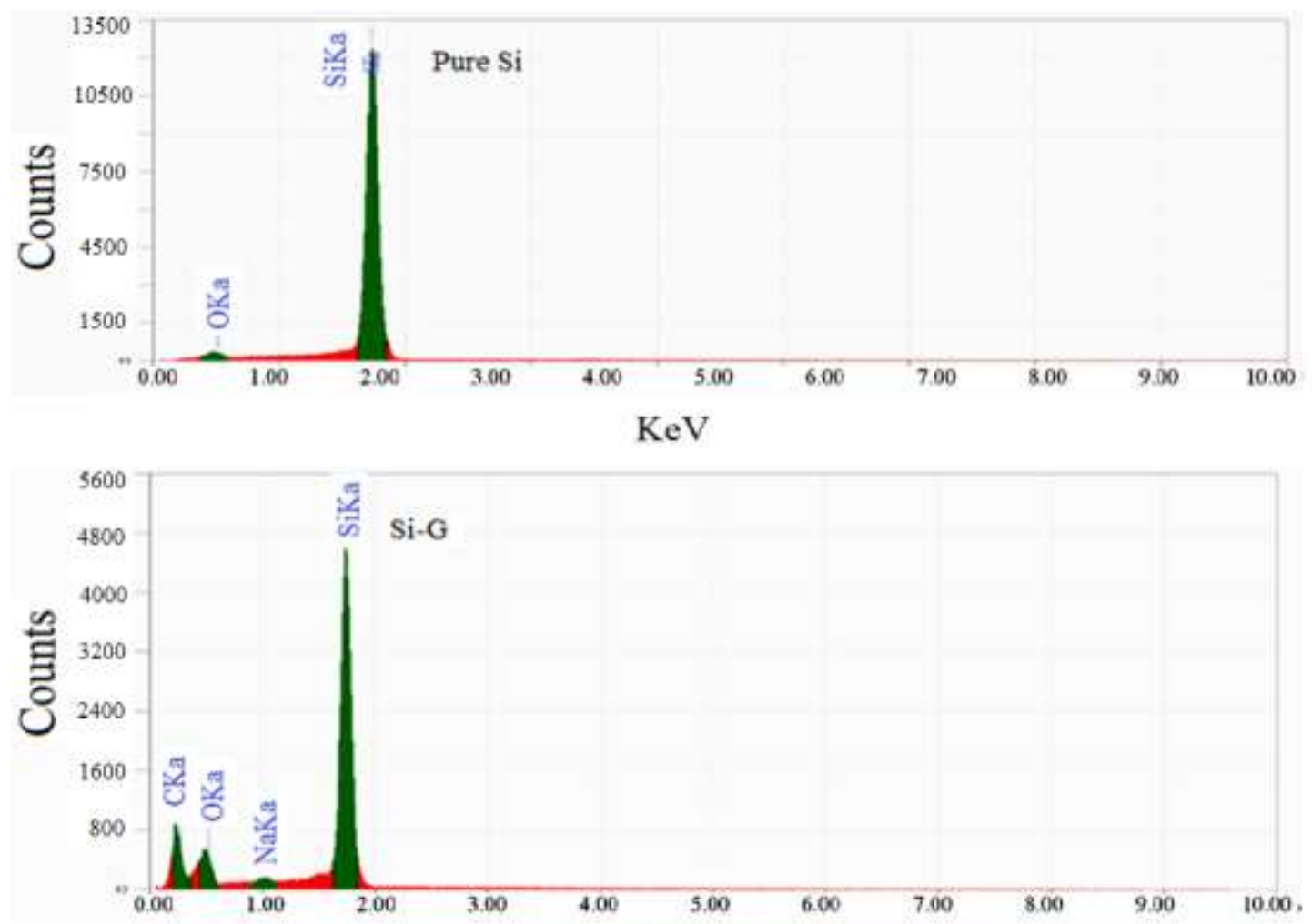

Fig. 1 EDAX graph for treated silicon and silicon-graphene samples.

There is little or no presence of micro-scale particles in contrast to pure silicon samples. Chargedischarge curves for alkaline etched $\mathrm{Si}$ and $\mathrm{Si}-\mathrm{G}$ samples $\mathrm{Vs} \mathrm{Na} / \mathrm{Na}^{+}$are presented in Figure 6. For comparison, pure graphene (commercial graphite nanoplatelets) electrode was tested as an electrode with the same specific current density. The theoretical capacity was assumed to be $160 \mathrm{~mA}$ per each gram of coated material on the $\mathrm{Cu}$ electrode (based on the formation of $\mathrm{Si}_{24} \mathrm{Na}_{4}$ alloy reported with orthorhombic $\mathrm{Si}$ )[10]. The discharge capacities of these electrodes at different $\mathrm{C}$ rates are summarized in Table 4 . The specific discharge capacity and first discharge coulombic efficiency reported for pure alkaline etched
Si electrode were very low to be used for application in $\mathrm{Na}$ ion batteries. The intrinsic low electronic conductivity of silicon and compact FFC structure form a barrier for reversible $\mathrm{Na}^{+}$ion insertion/extraction. The large first irreversible discharge capacity indicates the occurrence of alloying. According to charge calculations, the ratio of $\mathrm{Na}: \mathrm{Si}$ alloy was 1:3. Si-G electrode performance was much higher than both alkaline treated $\mathrm{Si}$ and untreated $\mathrm{G}$ electrodes. The average discharge potential decreases with increasing graphitic carbon part, which is favorable for anode materials [4]. CV curves in Figure $7 \mathrm{a}$, show the difference in $\mathrm{V}_{\text {oc }}$ between pure $\mathrm{Si}$ and $\mathrm{Si}$ $\mathrm{G}$ was more than $0.65 \mathrm{~V}$, and the $\mathrm{CV}$ plot area indicates the presence of higher capacity for Si-G electrode. 


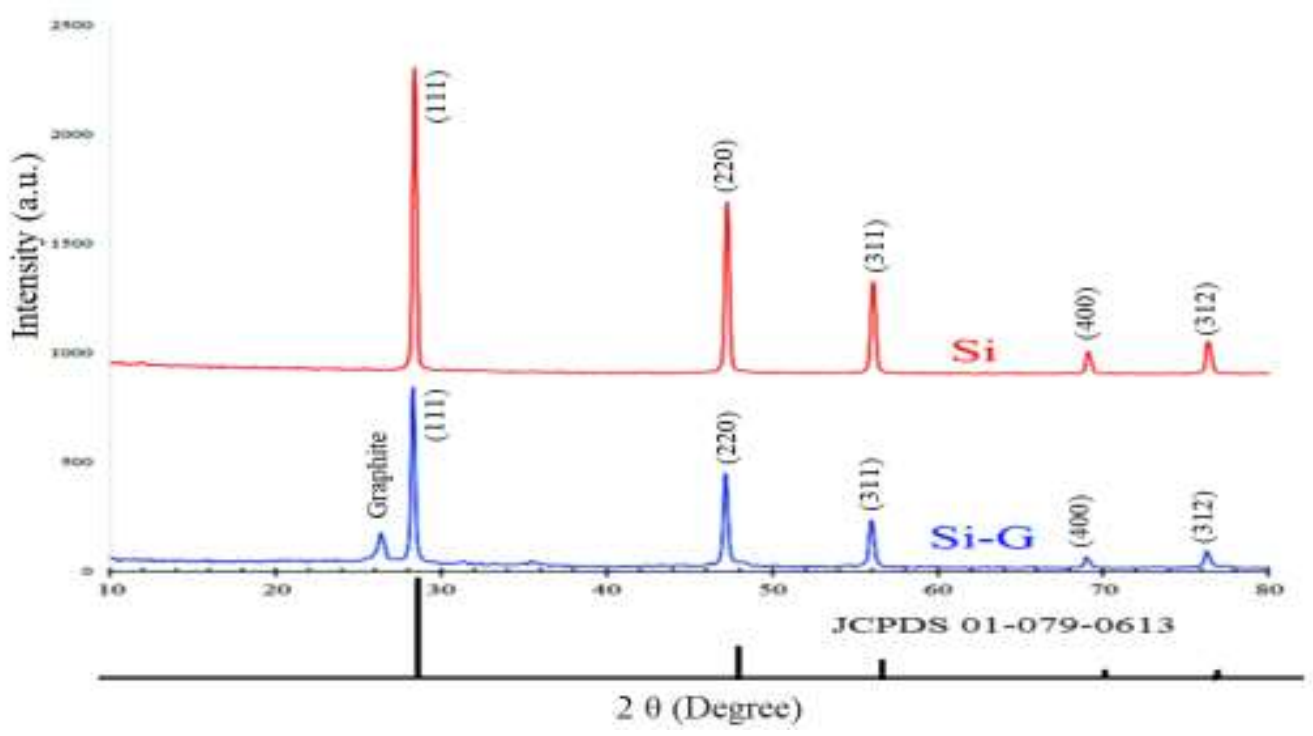

Fig. 2 XRD patterns for the anode samples ( $\mathrm{Si}$ and $\mathrm{Si}-\mathrm{G}$ ).

Table 2. Calculated crystallite sizes (D) for anode samples.

\begin{tabular}{|c|c|c|c|c|c|}
\hline \multirow{2}{*}{ Sample } & peak (hkl) & $\begin{array}{c}\mathbf{2 \theta} \\
(\mathbf{D e g r e e})\end{array}$ & FWHM & $\begin{array}{c}\text { crystallite size } \\
(\mathbf{n m})\end{array}$ & $\begin{array}{c}\text { Average crystallite size } \\
(\mathbf{n m})\end{array}$ \\
\hline \multirow{3}{*}{$\mathrm{Si}$} & $(111)$ & 28.36 & 0.27 & 31.7 & \multirow{2}{*}{33.15} \\
\cline { 2 - 5 } & $(220)$ & 47.23 & 0.278 & 32.56 & \\
\cline { 2 - 5 } & $(311)$ & 56.05 & 0.267 & 35.19 & \multirow{2}{*}{35.1} \\
\hline \multirow{3}{*}{$\mathrm{Si}-\mathrm{G}$} & $(111)$ & 28.26 & 0.25 & 34.64 & \\
\cline { 2 - 6 } & $(220)$ & 47.14 & 0.25 & 36.2 & \\
\cline { 2 - 6 } & $(311)$ & 55.96 & 0.27 & 34.5 & \\
\hline
\end{tabular}

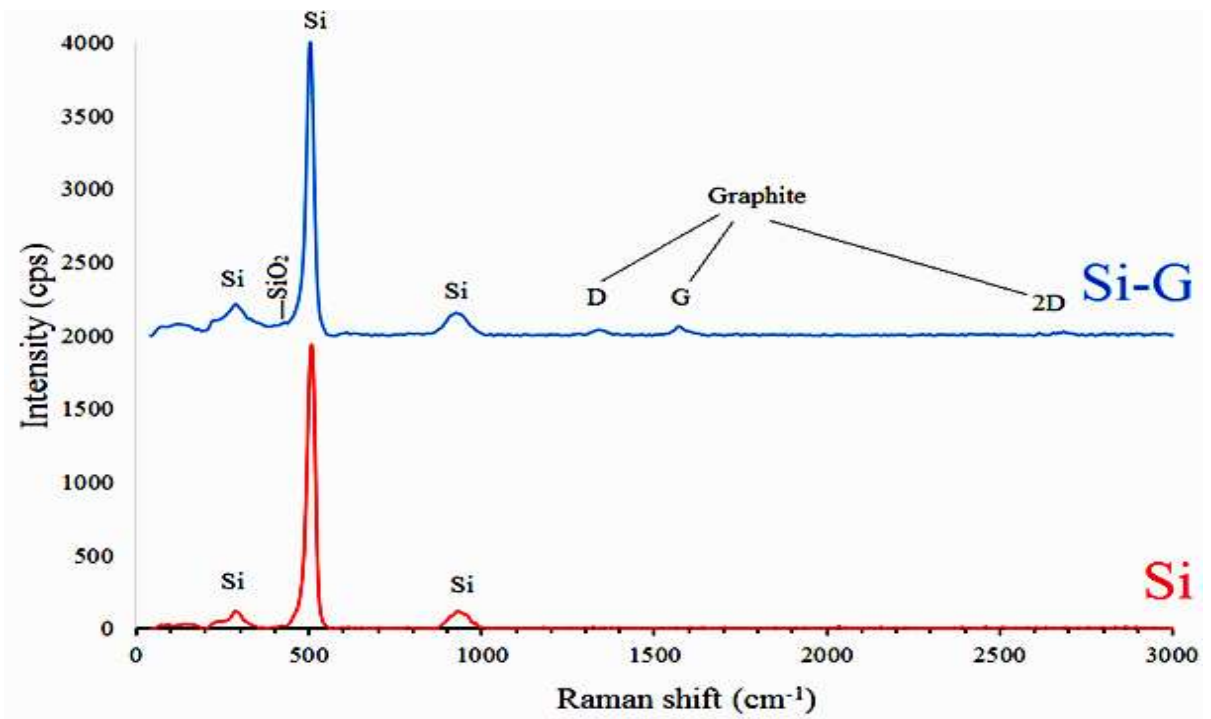

Fig. 3 Raman spectra for alkali etched $\mathrm{Si}$ and $\mathrm{Si}-\mathrm{G}$ samples. 


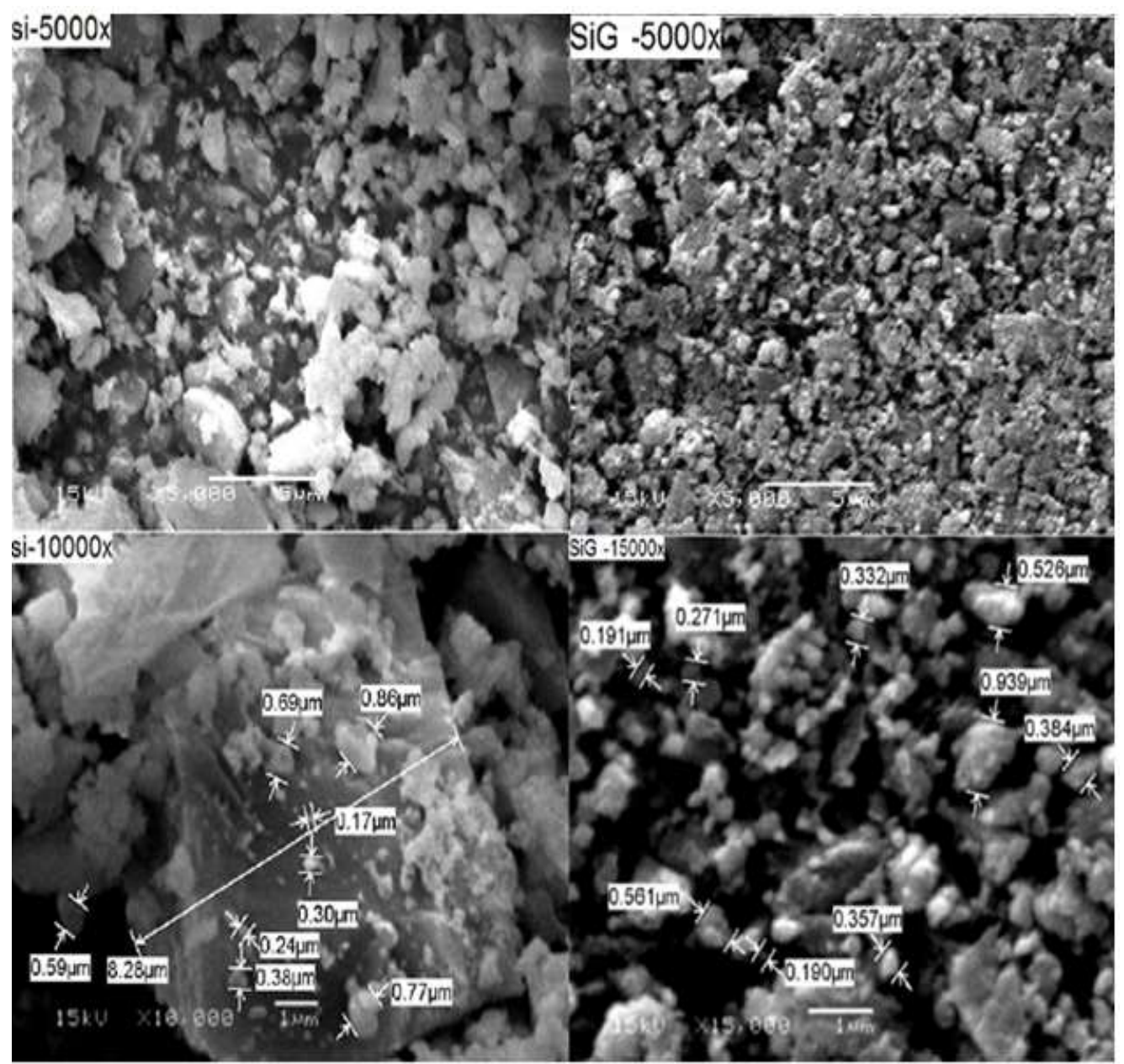

Fig. 4 SEM images for alkali etched $\mathrm{Si}$ and $\mathrm{Si}-\mathrm{G}$ samples at different magnifications.

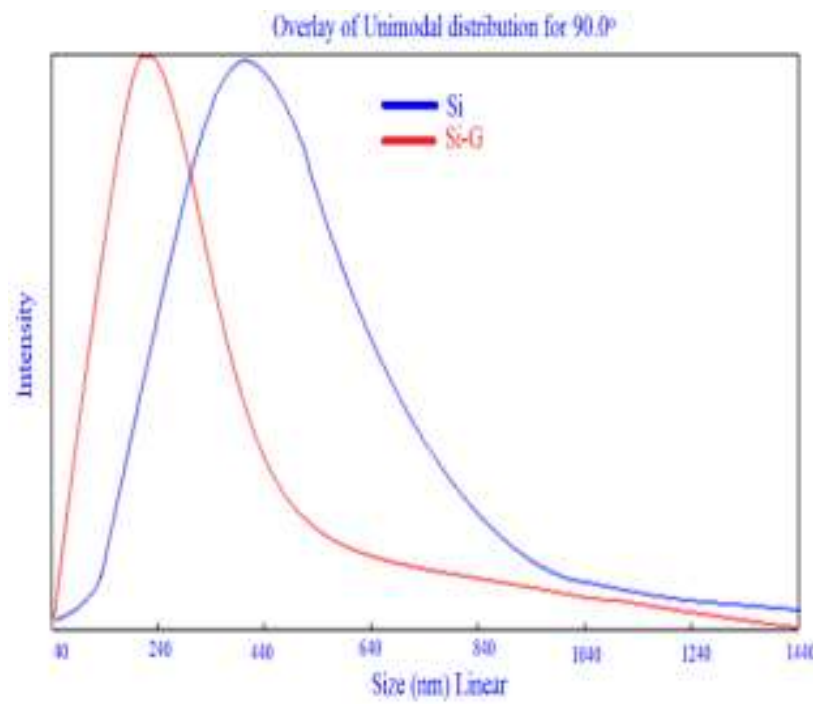

Fig. 5 Particle size distribution curves for $\mathrm{Si}$ and $\mathrm{Si}-\mathrm{G}$ samples.
Table 3. Mean particle sizes for $\mathrm{Si}$ and $\mathrm{Si}-\mathrm{G}$ samples.

\begin{tabular}{|c|c|c|}
\hline Sample & $\begin{array}{c}\text { SEM mean } \\
(\mathbf{n m})\end{array}$ & PSA mean \\
\hline Si & 1316 & 406.7 \\
\hline Si-G & 416.8 & 216.1 \\
\hline
\end{tabular}

The Si with graphene in weight ratio $2: 1$ perform a synergetic effect with each other, the graphene provides high electronic and ionic conductivity and silicon provide active sites for $\mathrm{Na}$ insertion [2].

EIS curves for $\mathrm{Si}, \mathrm{Si}-\mathrm{G}$, and $\mathrm{G}$ samples are shown in Figure $7 b$. 
Table 4. Discharge capacities of alkaline etched anodes at different $\mathrm{C}$ rates.

\begin{tabular}{|c|c|c|c|c|c|}
\hline \multirow{2}{*}{ Sample } & \multicolumn{2}{|c|}{$\begin{array}{c}\text { First Irreversible } \\
\text { discharge capacity }\end{array}$} & \multicolumn{2}{|c|}{ Specific reversible capacity (mAhg-1) } & \multirow{2}{*}{$\begin{array}{c}\text { Coulombic } \\
\text { efficiency of first } \\
\text { discharge cycle }\end{array}$} \\
\cline { 3 - 5 } & & $0.2 \mathrm{C}$ & $0.5 \mathrm{C}$ & $1 \mathrm{C}$ & $6.9 \%$ \\
\hline $\mathrm{Si}$ & 228.96 & 15.76 & 6.6 & $\mathrm{NA}$ & $40 \%$ \\
\hline $\mathrm{Si}-\mathrm{G}$ & 209.3 & 83.9 & 49.13 & 34.19 & $34.6 \%$ \\
\hline $\mathrm{G}$ & 37.23 & 12.88 & $\mathrm{NA}$ & $\mathrm{NA}$ & \\
\hline
\end{tabular}
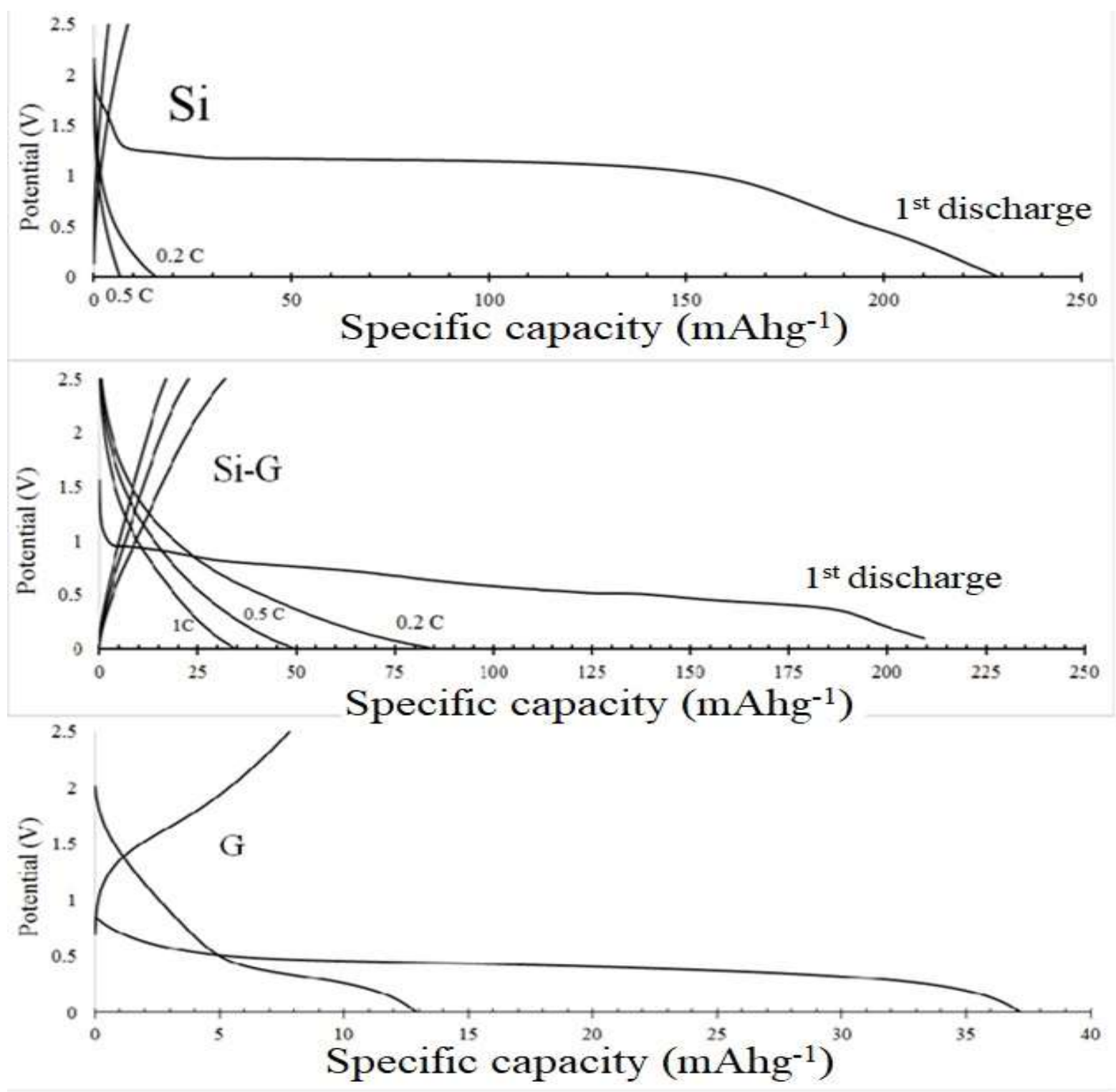

Fig. 6 Charge-discharge curves for alkaline etched $\mathrm{Si}$ and $\mathrm{Si}-\mathrm{G}$ samples $\mathrm{Vs} \mathrm{Na} / \mathrm{Na}^{+}$at different c rates compared to untreated graphene electrode. 

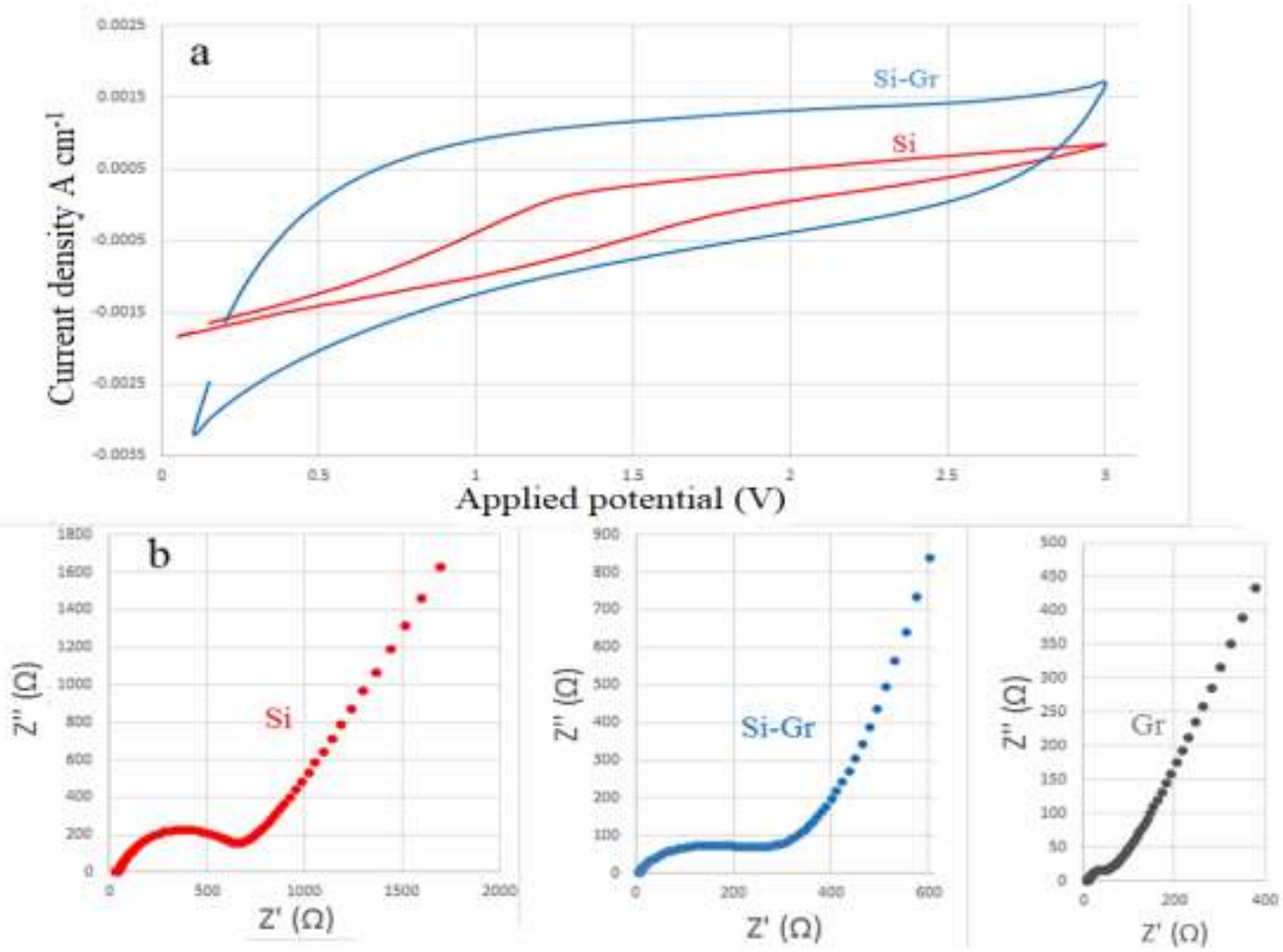

Fig. 7 a) Cyclic voltammetry curves for $\mathrm{Si}$ and $\mathrm{Si}-\mathrm{G}$ electrodes, and b) Nyquist plots for Si and Si-G electrodes compared to pure graphene electrode.

The increase in graphene nanoplatelet part decreases the charge transfer resistance $\left(\mathrm{R}_{\mathrm{ct}}\right)$ owing to its intrinsic high conductivity. In addition, the lower particle size and the relatively enhanced homogeneity of the sample's particle size and shape have enhanced the performance of the $\mathrm{Si}-\mathrm{G}$ electrodes [26]. However, the rate performance of $\mathrm{Si}-\mathrm{G}$ anode materials reported in this work is still behind many of the anode materials that were discussed previously in the literature.

\section{Conclusion}

Alkali etched porous silicon and porous silicongraphene composite was produced by a fast and lowcost method. Porous silicon with FCC structure was generally unable to reversibly intercalate sodium ions for sodium-ion battery application. The presence of commercial graphene during the etching and ball milling process relatively enhanced its morphology leading to a significant increase in its capacity and rate capability. It is recommended to study the effect of increasing-decreasing $\mathrm{Si}: \mathrm{G}$ ratio on the overall electrochemical performance of the material. It may be useful to use silicon powder with an orthorhombic structure instead of FCC silicon.

\section{References}

[1] M. V. Reddy, A. Mauger, C. M. Julien, A. Paolella, K. Zaghib, Brief history of early lithiumbattery development, Materials (Basel)., 13 (2020) 1884, doi: 10.3390/MA13081884.

[2] K. Chayambuka, G. Mulder, D. L. Danilov, P. H. L. Notten, Sodium-Ion Battery Materials and Electrochemical Properties Reviewed, Adv. Energy Mater., 8 (2018) 1800079, doi: 10.1002/aenm.201800079.

[3] B. Lee, E. Paek, D. Mitlin, S. W. Lee, Sodium Metal Anodes: Emerging Solutions to Dendrite Growth, Chem. Rev., 119 (2019) 5416-5460, doi: 10.1021/acs.chemrev.8b00642.

[4] H. Zhang, Y. Huang, H. Ming, G. Cao, W. Zhang, J. Ming, R. Chen, Recent advances in nanostructured carbon for sodium-ion batteries, J. Mater. Chem. A, 8 (2020)1604-1630, doi: 10.1039/c9ta09984k. 
[5] Q. Ni, R. Dong, Y. Bai, Z. Wang, H. Ren, S. Sean, F. Wu, H. Xu, C. Wu, Superior sodium-storage behavior of flexible anatase $\mathrm{TiO}_{2}$ promoted by oxygen vacancies, Energy Storage Mater., 25 (2020) 903-911, doi: 10.1016/j.ensm.2019.09.001.

[6] F. Xie, L. Zhang, Y. Jiao, A. Vasileff, D. Chao, S. Z. Qiao, Hydrogenated dual-shell sodium titanate cubes for sodium-ion batteries with optimized ion transportation, J. Mater. Chem. A, 8 (2020) 15829-15833, doi: 10.1039/d0ta00967a.

[7] Y. Park, D. S. Shin, S. H. Woo, N. S. Choi, K. H. Shin, S. M. Oh, K. T. Lee, S. Y. Hong, Sodium terephthalate as an organic anode material for sodium ion batteries, Adv. Mater., 24 (2012) 3562-3567, doi: 10.1002/adma.201201205.

[8] M. Lao, Y. Zhang, W. Luo, Q. Yan, W. Sun, S. X. Dou, Alloy-Based Anode Materials toward Advanced Sodium-Ion Batteries, Adv. Mater., 29 (2017) 1700622, doi: 10.1002/adma.201700622.

[9] Y. Yu, S. Hu, J. Huang, Adsorption and diffusion of lithium and sodium on the silicon nanowire with substrate for energy storage application: A first principles study, Mater. Chem. Phys., 253 (2020) 123243, doi: 10.1016/j.matchemphys.2020.123243.

[10] U. Arrieta, N. A. Katcho, O. Arcelus, J. Carrasco, First-principles study of sodium intercalation in crystalline $\mathrm{Na}_{x} \mathrm{Si}_{24}(0 \leq \mathrm{x} \leq 4)$ as anode material for Na-ion batteries, Sci. Rep., 7 (2017) 5350, doi: 10.1038/s41598-017-05629-X.

[11] S. C. Jung, D. S. Jung, J. W. Choi, Y. K. Han, Atom-level understanding of the sodiation process in silicon anode material, J. Phys. Chem. Lett., 5 (2014) 1283-1288, doi: 10.1021/jz5002743.

[12] C. Y. Chou, M. Lee, G. S. Hwang, A Comparative First-Principles Study on Sodiation of Silicon, Germanium, and Tin for Sodium-Ion Batteries, J. Phys. Chem. C, 119 (2015) 14843-14850, doi: 10.1021/acs.jpcc.5b01099.

[13] Y. Xu, E. Swaans, S. Basak, H. W. Zandbergen, D. M. Borsa, F. M. Mulder, Reversible Na-ion uptake in Si nanoparticles, Adv. Energy Mater., 6 (2016) 1501436, doi: 10.1002/aenm.201501436.

[14] A. Casimir, H. Zhang, O. Ogoke, J. C. Amine, J. $\mathrm{Lu}, \mathrm{G}$. Wu, Silicon-based anodes for lithium-ion batteries: Effectiveness of materials synthesis and electrode preparation, Nano Energy, 27 (2016) 359-376, doi: 10.1016/j.nanoen.2016.07.023.

[15] A. H. Kashyout, H. M. A. Soliman, M. Nabil, A. A. Bishara, Fabrication of nano-porous silicon using alkali etching process, Mater. Lett., 100
(2013) 184-187, doi: 10.1016/j.matlet.2012.12.107.

[16] P.K. Singh, R. Kumar, M. Lal, S.N. Singh, B. Das, Electiveness of anisotropic etching of silicon in aqueous alkaline solutions, Sol. Energy Mater. Sol. Cells, 70 (2001)103-113, doi: 10.1016/S0927-0248(00)00414-1.

[17] I. Zubel, I. Barycka, K. Kotowska, M. X. Kramkowska, "Silicon anisotropic etching in alkaline solutions IV the effect of organic and inorganic agents on silicon anisotropic etching process, Sensors Actuators, A Phys., 87 (2001) 163-171, doi: 10.1016/S0924-4247(00)00481-7.

[18] Fundamental physical constants, Concepts in Magnetic Resonance, 6 (1994) 68, doi:10.1002/cmr.1820060106.

[19] S. Baruah, S. Kumar, B. Nayak, A. Puzari, Optoelectronically suitable graphene oxidedecorated titanium oxide/polyaniline hybrid nanocomposites and their enhanced photocatalytic activity with methylene blue and rhodamine B dye, Polym. Bull., 78 (2021) 17031720, doi: 10.1007/s00289-020-03182-8.

[20] P. Li, G. Zhao, X. Zheng, X. Xu, C. Yao, W. Sun, S. X. Dou, Recent progress on silicon-based anode materials for practical lithium-ion battery applications, Energy Storage Mater., 15 (2018) 422-446, doi: 10.1016/j.ensm.2018.07.014.

[21] K. Uchinokura, T. Sekine, E. Matsuura, Raman scattering by silicon, Solid State Commun., 11 (1972) 47-49, doi: 10.1016/00381098(72)91127-1.

[22] V.V. Kidalov C.A. Кукушкин, А.В. Осипов, A.V. Redkov, A.C. Гращенко, I.P. Soshnikov, M.E. Boiko, M.D. Sharkov, A.F. Dyadenchuk, Growth of sic films by the method of substitution of atoms on porous si (100) and (111) substrates, Mater. Phys. Mech., 36 (2018) 39-52, doi: 10.18720/MPM.3612018_4.

[23] R. K. Biswas, P. Khan, S. Mukherjee, A. K. Mukhopadhyay, J. Ghosh, K. Muraleedharan, Study of short range structure of amorphous Silica from PDF using Ag radiation in laboratory XRD system, RAMAN and NEXAFS, J. Non. Cryst. Solids, 488 (2018) 1-9, doi: 10.1016/j.jnoncrysol.2018.02.037.

[24] Y. Kobayashi, S. Matsuda, K. Imamura, H. Kobayashi, Hydrogen generation by reaction of Si nanopowder with neutral water, J. Nanoparticle Res., 19 (2017) 176, doi: 10.1007/s11051-0173873-z.

[25] L. Liu, M. Zhou, L. Jin, L. Li, Y. Mo, G. Su, X. Li, H. Zhu, Y. Tian, Recent advances in friction 
and lubrication of graphene and other 2D materials: Mechanisms and applications, Friction, 7 (2019) 199-216, doi: 10.1007/s40544-0190268-4.

[26] L. Shi, T. S. Zhao, A. Xu, J. B. Xu, Ab initio prediction of a silicene and graphene heterostructure as an anode material for $\mathrm{Li}$ - and Na-ion batteries, J. Mater. Chem. A, 4 (2016) 16377-16382, doi: 10.1039/c6ta06976b. 